\title{
Sistem Ujian Online Essay Kolektif Berbasis Gambar Studi Kasus Kampus PTKI Medan
}

\author{
Abdul Azis Rahmansyah",*, Poltak Evencus Hutajulu² \\ ${ }^{1}$ Teknik Mekanika, Politeknik Teknologi Kimia Indutri, Medan, Indonesia \\ ${ }^{2}$ Agribisnis Kelapa Sawit, Politeknik Teknologi Kimia Industri, Medan, Indonesia \\ Email: 1," azis@ptki.ac.id, ${ }^{2}$ pol_evencus@ptki.ac.id \\ Email Penulis Korespondensi: azis@ptki.ac.id
}

\begin{abstract}
Abstrak-Pandemi Covid-19 menjadi musibah untuk kita semua, Pendidikan Vokasi juga terkena imbas dari pandemi Covid19 tersebut yang memaksa untuk perkuliahan secara secara daring salah satunya di Politeknik Teknologi Kimia Industri (PTKI), dalam pelaksanaan ujian di PTKI Medan dilaksanakan secara kolektif dengan soal ujian berupa essay. Telah banyak penelitian tentang ujian online essay tetapi lingkup pembahasan untuk koreksi otomatis ataupun kemiripan berdasarkan text input. Pada pendidikan vokasi khususnya PTKI Medan yang memiliki ujian tidak sebatas text input tetapi terdapat perhitungan. Kelemahan lain dari text input adalah jawaban dapat lebih mudah di copy paste oleh mahasiswa. Penelitian ini dilaksanakan selama 1 tahun mulai semester Ganjil 2020 sampai dengan Genap 2020. Metode dalam pengembangan sistem informasi menggunakan model waterfall dengan tahapan analisis kebutuhan, design sistem, pengkodean, implementasi dan tahapan terakhir pemeliharaan sistem. Dari hasil penelitian pada semester ganjil 2020 peneliti menggunakan model ujian online essay berbasis text tetapi terdapat kelemahan yang ditemukan salah satunya mudahnya mahasiswa dalam menggunakan jawaban dari internet yang langsung di masukkan ke kolom jawaban. Pada tahapan pemeliharaan peneliti melakukan pengembangan sistem dengan mengganti model ujian berbasis gambar, sehingga mahasiswa harus menulis jawabannya ke kertas lalu mengupload jawaban ke dalam website. Sistem upload file dapat membebani server jika tidak di kontrol, salah satu teknik yang digunakan adalah mengkompress file gambar yang di upload oleh mahasiswa ke sistem dan di peroleh maksimal size bisa di kompres sampai dengan 78,48\% dari ukuran $1329 \mathrm{~Kb}$ menjadi $286 \mathrm{~Kb}$ untuk tipe data png. Selain itu untuk memudahkan dosen dalam memeriksa jawaban memanfaatkan fitur ezoom.js sebagai sarana untuk view jawaban dalam bentuk gambar yang berguna untuk memperbesar, memperkecil, memutar gambar jawaban. Ezoom.js merupakan salah satu javascript yang dapat di pasang pada website berbasis php.
\end{abstract}

Kata Kunci: Ujian Online; Essay; Kolektif; Kompres Gambar; Ezoom

Abstract-The Covid-19 pandemic is a disaster for all of us, Vocational Education is also affected by the Covid-19 pandemic which forces online lectures, one of which is at the Industrial Chemical Technology Polytechnic (PTKI), in the implementation of the exam at PTKI Medan carried out collectively with questions exam in the form of an essay. There have been many studies on online essay exams but the scope of the discussion is for automatic correction or similarity based on text input. In vocational education, especially PTKI Medan, which has a test that is not limited to text input but there are calculations. Another weakness of text input is that the answers can be more easily copied and pasted by students. This research was carried out for 1 year starting from Odd semester 2020 to Even 2020. The method in developing information systems uses the waterfall model with the stages of needs analysis, system design, coding, implementation and the last stage of system maintenance. From the results of the research in the odd semester of 2020, the researchers used a text-based online essay exam model, but many weaknesses were found, one of which was the ease of students in using answers from the internet which were directly entered into the answer column. At the maintenance stage, the researcher updates the system by changing the image-based exam model, so students must write their answers on paper and then upload the answers to the website. The file upload system can overload the server if it is not controlled, one of the techniques used is to compress image files uploaded by students to the system and the maximum size can be compressed up to $78.48 \%$ from $1329 \mathrm{~Kb}$ to $286 \mathrm{~Kb}$ for this type. png data. In addition, to make it easier for lecturers to check answers, use the ezoom.js feature as a means to view answers in the form of images that are useful for zooming in, zooming out, rotating the answer images. Ezoom.js is a javascript that can be installed on php-based websites.

Keywords: Online Exam; Essays; Collective; Compress Images; Ezoom

\section{PENDAHULUAN}

Pandemi Covid 19 menjadi musibah untuk seluruh penduduk khususnya di Indonesia. Seluruh segmen kehidupan menjadi terganggu, hal ini juga berdampak pada pendidikan yang memaksa proses pembelajaran di lakukan secara online. Proses ini berjalan pada skala yang belum terukur dan teruji karena hal ini belum pernah terjadi sebelumnya[1]. Tetapi model pembelajaran online berbasis digital di nilai tepat karena resiko penularan covid-19 dapat terjadi jika kegiatan pembelajaran dilakukan secara tatap muka yang dapat menyebabkan peningkatan penyebaran virus tersebut[2].

Kampus Politeknik Teknologi Kimia Industri (PTKI) yang berada di Medan, Sumatera Utara. Sebelum Pandemi Covid-19 terjadi kegiatan perkuliahan dilaksanakan secara tatap muka di dalam kelas. Di mana proses belajar mengajar baik teori maupun praktikum dilakukan secara tatap muka. Walaupun masih menggunakan metode konvensional yang memerlukan banyak sumber daya, PTKI Medan telah memiliki sistem inform asi akademik berbasis website yang menjadi titik temu pelaporan data ke DIKTI mulai proses pengisian Kartu Rencana Studi (KRS) hingga proses melihat Kartu Hasil Studi (KHS). Pada proses pembelajaran selama pandemi covid-19 banyak metode yang digunakan oleh pengajar di PTKI Medan[3], selain pengajaran, pandemi covid-19 juga berdampak pada proses ujian yang biasa dilaksanakan pada pertengahan semester dan akhir semester yang 
menjadi sarana evaluasi hasil pembelajaran[4]. Proses ujian dilaksanakan secara kolektif pada minggu tertentu. Ujian semester bertujuan untuk menguji kemampuan mahasiswa dalam memahami materi yang telah diajarkan saat perkuliahan berlangsung[5]. Model ujian semester di PTKI Medan adalah bentuk tes uraian. Penjelasan tentang tes uraian [6] untuk menguji pemahaman dari mahasiswa dengan menjawab soal-soal yang diberikan baik jawaban singkat, penjelasan maupun hitungan. Setiap pembelajaran memiliki kelebihan dan kekurangan terutama di masa pandemi Covid-19 ini[7], sehingga pengajar dituntut untuk kreatif dalam melakukan proses pembelajaran di masa ini. Walaupun terdapat kesulitan dalam beradaptasi pengajar dan siswa dalam perubahan metode pembelajaran vokasi dari konvensional menjadi online[2] di masa pandemi covid-19 perubahan tersebut harus tetap di jalani agar proses pembelajaran tidak terhenti, selain itu juga infrastruktur jaringan internet belum merata untuk tiap daerah di Indonesia.

Pengembangan sistem ujian online berbasis essay telah banyak dilakukan di antaranya penelitian tentang sistem koreksi jawaban esai otomatis di mana sistem yang digunakan oleh peneliti menggunakan form isian text. Dengan metode Vector Space Model peneliti mengukur tingkat kemiripan antara jawaban dari peserta dengan kunci jawaban[8]. Selain itu peneliti yang lain juga melakukan pengembangan dengan menggabungkan metode Latent Semantic Analysis (LSA) untuk menangani synonim dan polysemi antara index term pada text yang diinput[9]. Penelitian yang lain terkait sistem ujian online essay dengan menggunakan algoritma Rabin Karp [10] dan juga menggunakan TF-IDF dalam pencocokan text[10], [11] dalam penelitian tersebut peneliti berhasil meningkatkan hasil pencocokan text dalam dokumen atau jawaban yang di input pada form text. Penelitian [12], [13] menggambarkan bahwa kelebihan lain dengan sistem online adalah meminimalkan biaya ujian online seperti pencetakan soal serta dapat memudahkan untuk pengajar yang melakukan pemeriksaan secara online untuk jawaban siswa di mana pun pengajar tersebut berada. Kelebihan-kelebihan dari penelitian sebelumnya merupakan hal yang baik tetapi penerapan pada perkuliahan yang memiliki hitungan mungkin akan berbeda dengan ujian yang tanpa hitungan. Selain itu, ujian online berbasis text walaupun telah di rancang secara baik dalam melakukan koreksi otomatis tetapi tidak bisa membatasi mahasiswa dalam menduplikat jawaban baik inform asi dari internet maupun inform asi dari orang lain. Berdasarkan hal tersebut penelitian ini memfokuskan pada merancang model ujian semester essay secara online di masa pandemi covid-19.

\section{METODOLOGI PENELITIAN}

Dalam penelitian ini dibagi menjadi dua bagian yaitu melengkapi kebutuhan data dan pengembangan sistem informasi.

\subsection{Pengumpulan data}

Sebelum melakukan pengembangan sistem ujian online berbasis website peneliti terlebih dahulu mengumpulkan data awal yang menjadi bahan pertimbangan dalam pembuatan sistem dengan 3 metode yaitu :

a. Observasi.

Melakukan pengamatan langsung di PTKI Medan pada saat proses ujian berlangsung sebagai bentuk pemahaman terhadap sistem yang berjalan secara offline dan digambarkan dalam bentuk flowchart seperti pada Gambar 2.

b. Studi Literatur.

Pengumpulan data berdasarkan jurnal dan penelitian terdahulu terkait ujian online uraian secara kolektif.

c. Wawancara.

Peneliti melakukan wawancara kepada pihak terkait akademik di PTKI Medan yaitu Pembantu Direktur 1

Bidang akademik dan Kepala Sub Bagian Pendidikan terkait proses Ujian Semester di PTKI Medan.

\subsection{Pengembangan Sistem dengan Model Waterfall}

Selain mengumpulkan data, model yang digunakan untuk menyelesaikan penelitian ini adalah model waterfall [14] dengan System Development Life Cycle (SDLC) seperti pada Gambar 1. Walaupun tergolong klasik model ini sangat banyak digunakan oleh para engginer untuk membuat program maupun sistem inform asi.

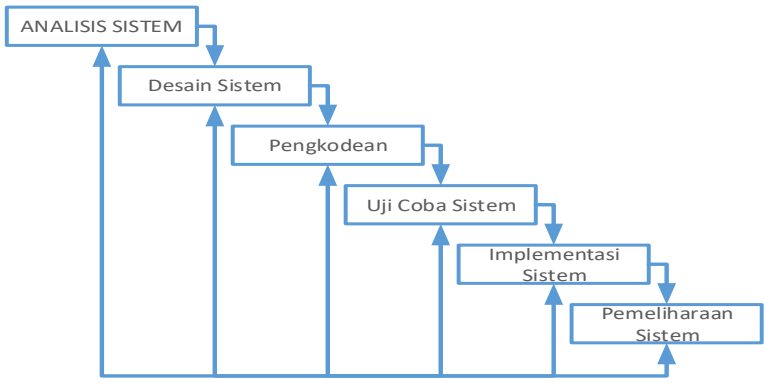

Gambar 1. Skematik Model SDLC Waterfall 
ISSN 2614-5278 (media cetak), ISSN 2548-8368 (media online)

Available Online at https://ejurnal.stmik-budidarma.ac.id/index.php/mib DOI 10.30865/mib.v5i3.3029

\subsubsection{Analisis Sistem Existing}

Pada tahapan ini peneliti menganalisis permasalahan dengan cara studi literatur terhadap sistem yang telah ada di PTKI Medan.

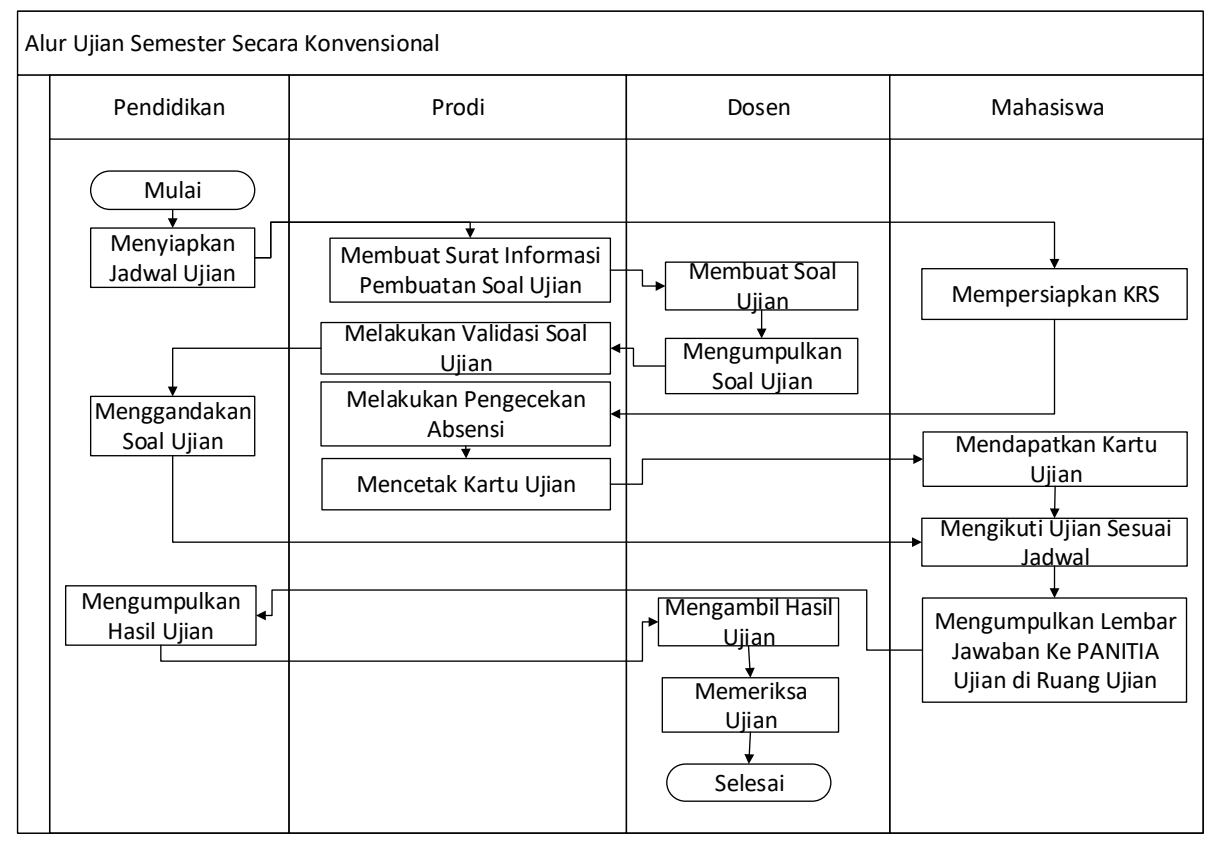

Gambar 2. Alur Ujian Semester sebelum pandemi di PTKI Medan

Dari Gambar 2 tersebut proses ujian di PTKI Medan berawal dari bagian pendidikan yang membuat jadwal ujian. Dosen akan menerima jadwal ujian berdasarkan surat edaran dari Prodi untuk pembuatan soal ujian. Soal ujian tersebut akan di validasi terlebih dahulu oleh prodi untuk pengecekan apakah telah sesuai dengan RPS yang telah diberikan pada semester awal perkuliahan sebelum di lakukan penggandaan oleh Pendidikan. Setiap mahasiswa sebelum mengambil kartu ujian terlebih dahulu mereka menyiapkan KRS dan terdapat syarat untuk mendapatkan kartu ujian yaitu untuk Ujian Tengah Semester (UTS) minimal pertemuan yang diikuti adalah 5 Pertemuan dari total 7 Pertemuan dan untuk Ujian Akhir Semester (UAS) minimal 11 Pertemuan dari 14 Pertemuan Efektif. Mahasiswa yang di perbolehkan mengikuti ujian akan mengikuti ujian sesuai jadwal yang telah di tetapkan dengan waktu pengerjaan sesuai standar yang ada di PTKI Medan yaitu 75 Menit untuk satu mata kuliah. Hasil ujian akan dikumpulkan oleh pengawas ujian saat ujian telah selesai dan semua lembar jawaban disimpan sementara di Pendidikan sebelum didistribusikan ke dosen yang menjadi pengampuh mata kuliah.

\subsubsection{Desain Sistem Usulan}

Berdasarkan alur pada Gambar 2, untuk mengkonversi dari model konvensional menjadi model online terdapat beberapa hal yang harus di perhatikan yaitu :

a. Proses penjadwalan ujian

b. Proses pembuatan soal ujian

c. Proses validasi soal ujian

d. Syarat mengikuti Ujian untuk Mahasiswa

e. Monitoring Proses Ujian

f. Memeriksa Hasil Ujian

Berdasarkan gambar 3 terdapat beberapa tahap agar proses ujian dapat berlangsung sebagaimana mestinya dan untuk menentukan jadwal diperlukan list data mata kuliah yang telah tersusun berdasarkan program studi, semester dan nama dosen yang menjadi pengampuh mata kuliah. Sedangkan untuk melakukan input soal ujian dilakukan oleh dosen yang bersangkutan berdasarkan data yang di input oleh pendidikan. Soal ujian yang di input dapat di validasi oleh program studi dan dapat di arsipkan. Jadwal yang telah di input oleh pendidikan tidak langsung dapat langsung dilihat oleh mahasiswa tetapi mahasiswa akan di cek jumlah kehadiran terlebih dahulu sebagai syarat untuk mengikuti ujian. Proses ujian berdasarkan jadwal yang telah ditentukan. Dan jawaban secara otomatis tersimpan di database agar dosen yang menjadi pengampuh mata kuliah dapat melihat jawaban dari mahasiswa yang mengikuti ujian.

Berdasarkan uraian dari gambar 3 maka dibentuk 3 bagian yang terdiri dari blok A yang berhubungan dengan user pendidikan/admin yang bertindak sebagi manajemen alur ujian, blok B yang berhubungan dengan user dosen dan blok C yang berhubungan dengan user mahasiswa seperti yang terlihat pada Gambar 4. 
ISSN 2614-5278 (media cetak), ISSN 2548-8368 (media online)

Available Online at https://ejurnal.stmik-budidarma.ac.id/index.php/mib DOI 10.30865/mib.v5i3.3029

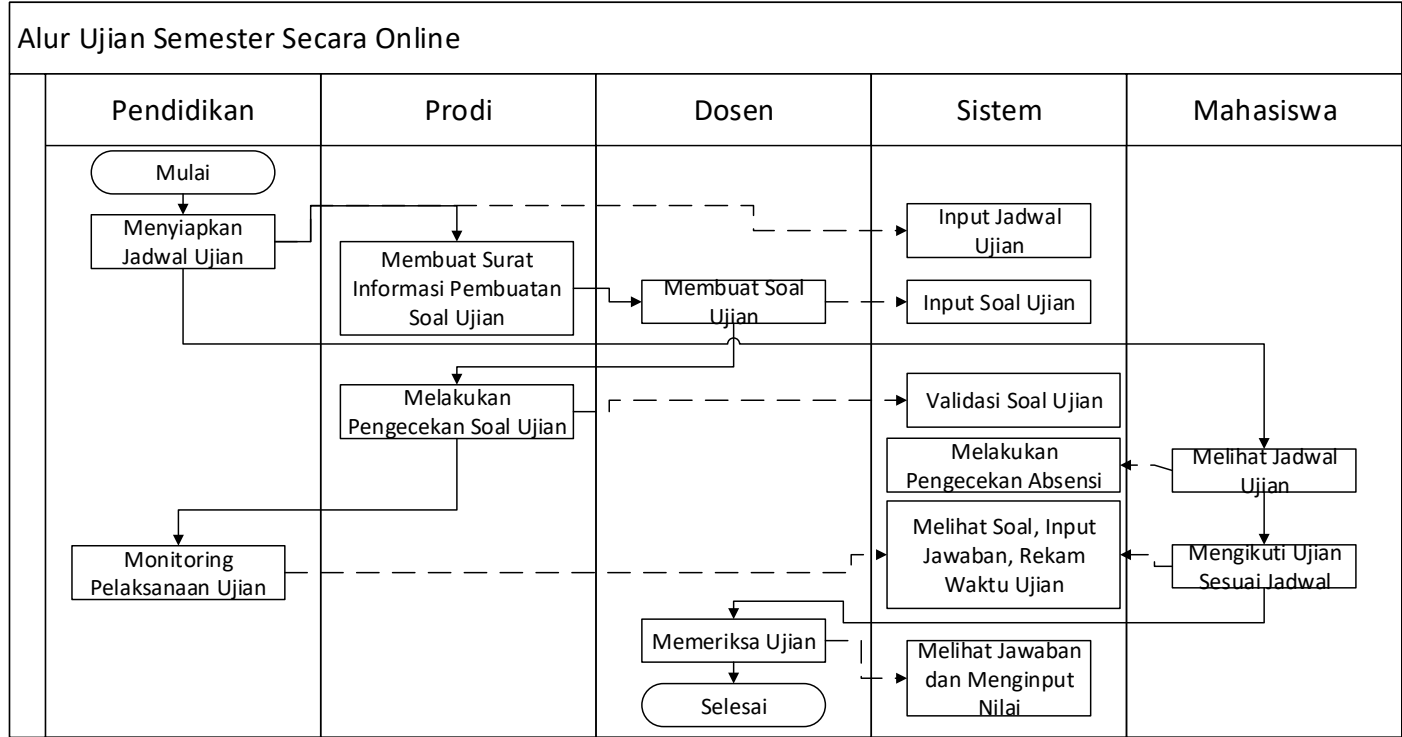

Gambar 3. Activity diagram Usulan

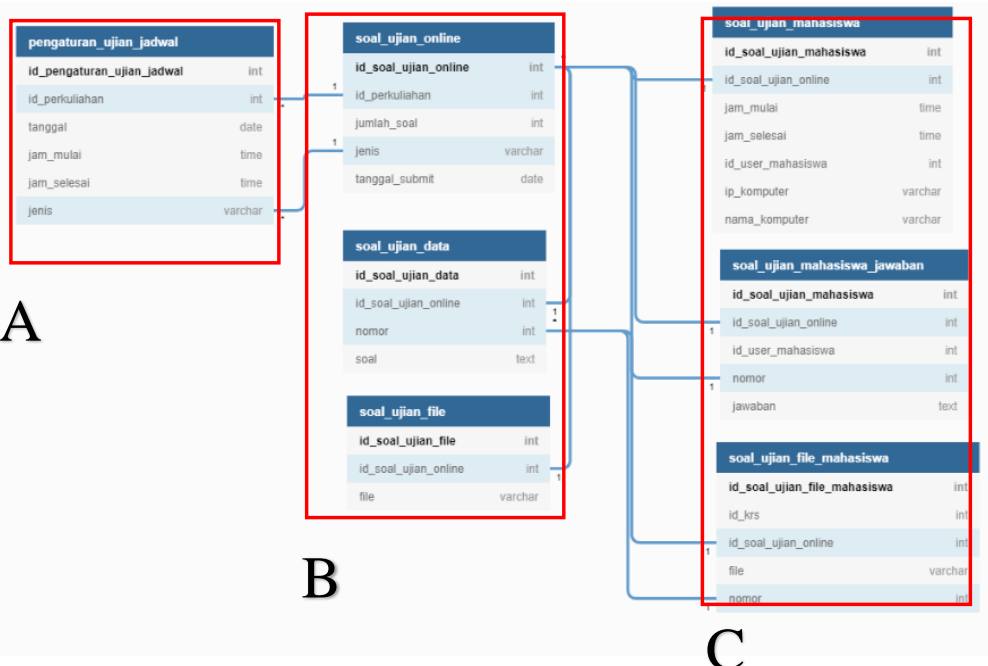

Gambar 4. Relasi Rancangan Tabel database

\subsubsection{Pengkodean}

Pada tahapan ini peneliti melakukan pengkodean menggunakan PHP (Hypertext PreProcessor) merupakan bahasa komputer/bahasa pemrograman yang digunakan untuk mengolah data dari server untuk ditampilkan di website [15]. Dan untuk melengkapi pengkodenan PHP digunakan juga JavaScript yang digunakan dalam pengembangan website agar lebih dinamis dan interaktif [16]. Sedangkan untuk database menggunakan kode program MySQL.

\subsubsection{Ujicoba Sistem}

Sistem di uji pada lokal komputer sebelum di upload masuk ke server menggunakan perantara aplikasi XAMPP [17]. Aplikasi XAMPP salah satu aplikasi open source yang memiliki fitur lengkap seperti Apache dan MySQL dan versi php 8.0.7 yang telah dimuat untuk XAMPP versi terakhir (XAMPP Versi 7.4.20 https://www.apachefriends.org/index.html, akses Juni 2021)

\subsubsection{Implementasi Sistem}

Selesai tahapan ujicoba sistem, sistem lalu di upload ke server yang menggunakan sistem operasi Linux. Implementasi ini langsung melibatkan pengguna yaitu dosen dan mahasiswa serta bagian administrasi pendidikan di PTKI Medan.

\subsubsection{Pemeliharaan Sistem}

Tahapan terakhir adalah tahapan pemeliharaan, pemeliharaan pada sistem inform asi dilakukan secara bertahap terhadap sistem inform asi yang telah diimplementasikan. Pemeliharaan ini dilakukan secara berkala melihat kondisi penyimpanan server dan aktivitas pengiriman data saat ujian sedang berlangsung ataupun pemeliharan yang sifatnya masukan jika saat sistem sedang berjalan ditemukan bug atau error. 
ISSN 2614-5278 (media cetak), ISSN 2548-8368 (media online)

Available Online at https://ejurnal.stmik-budidarma.ac.id/index.php/mib

DOI 10.30865/mib.v5i3.3029

\section{HASIL DAN PEMBAHASAN}

3.1 Perancangan UML

Sistem ini dapat berjalan sesuai yang di design usulan. Pada tahapan awal hasil analisa perancangan sistem didokumentasikan menggunakan Unified Model Language (UML)

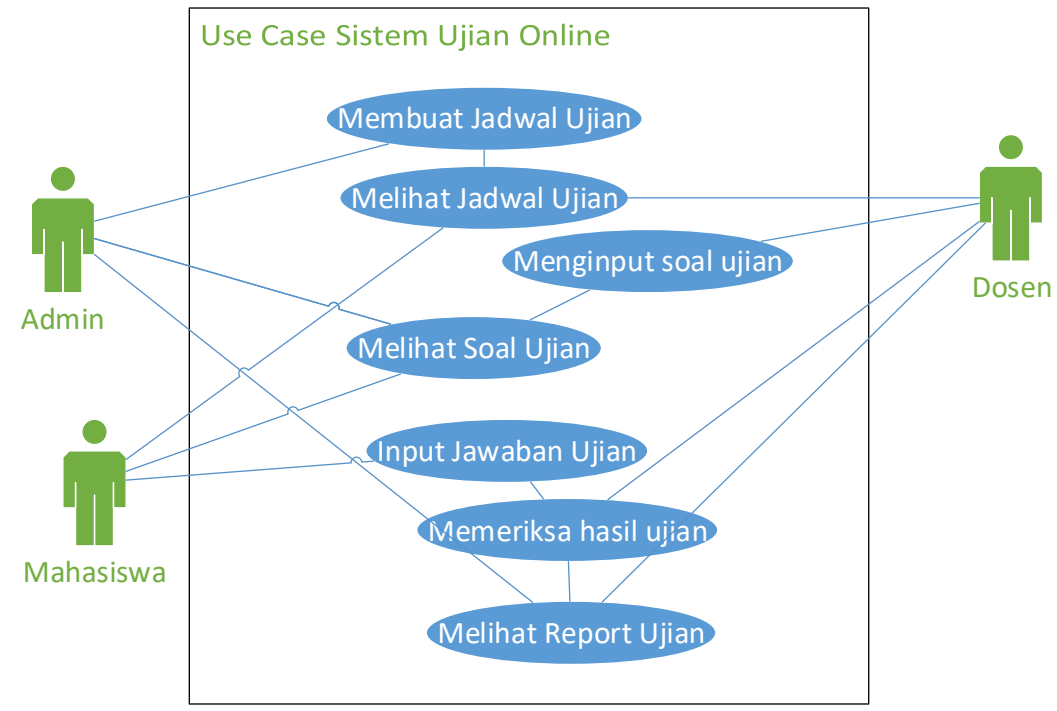

Gambar 5. Use Case Diagram Sistem Ujian Online

Pada gambar 5 memperlihatkan use case diagram sistem ujian online pada penelitian ini. Penjelasan lebih lanjut dijelaskan pada tabel 1 .

Tabel 1. Keterangan use case diagram

\begin{tabular}{ll}
\hline \multicolumn{1}{c}{ Use Case } & \multicolumn{1}{c}{ Keterangan } \\
\hline Membuat Jadwal Ujian & $\begin{array}{l}\text { Use Case ini hanya dapat di akses oleh Admin dalam hal ini adalah bagian } \\
\text { pendidikan untuk menginput jadwal ujian untuk tiap mata kuliah. Data yang di } \\
\text { input berupa tanggal pelaksanaan ujian, jam mulai, jam selesai. }\end{array}$ \\
\hline Melihat Jadwal Ujian & $\begin{array}{l}\text { Pada use case ini Mahasiswa dan Dosen dapat melihat jadwal sesuai dengan jadwal } \\
\text { mata kuliah yang di input oleh admin. }\end{array}$ \\
\hline Menginput Soal Ujian & $\begin{array}{l}\text { Use case ini hanya dapat aktif jika jadwal telah di input oleh admin selama jadwal } \\
\text { belum di input fitur ini akan ter-disable. }\end{array}$ \\
\hline Melihat Soal Ujian & $\begin{array}{l}\text { Use case ini dapat di akses oleh admin dan mahasiswa tetapi memiliki 2 perlakukan } \\
\text { yang berbeda. Untuk admin dapat mengakses kapan saja sedangkan untuk } \\
\text { mahasiswa soal ujian yang telah di input oleh dosen dapat di akses jika jadwal ujian } \\
\text { sedang berlangsung. }\end{array}$ \\
\hline Memput Jawaban Ujian & $\begin{array}{l}\text { Use case ini hanya akan aktif jika jadwal ujian telah masuk dan user mahasiswa } \\
\text { harus login terlebih dahulu untuk melihat soal ujian dan melihat tampilan input } \\
\text { jawaban ujian. }\end{array}$ \\
\hline Mse case ini aktif jika dan dapat di akses jika jadwal ujian sedang berlangsung \\
ataupun jadwal telah selesai. Dan use case ini hanya dapat di akses oleh dosen \\
pengampuh mata kuliah
\end{tabular}

\subsection{Hasil Rancangan}

Untuk hasil rancangan dapat di pada tahapan berikut :

a. Proses penjadwalan ujian

Pada tahapan ini operator pendidikan yang mengatur jadwal ujian akan menginput jadwal ujian secara online pada Halaman edit jadwal Ujian. Dengan Melakukan klik pada tombol Input MID/Input UAS seperti pada Gambar 7a. Setelah memilih mata kuliah yang akan di input jadwalnya selanjutnya menentukan tanggal, jam mulai, dan jam selesai seperti yang terlihat pada gambar $7 \mathrm{~b}$. 
JURNAL MEDIA INFORMATIKA BUDIDARMA

Volume 5, Nomor 3, Juli 2021, Page 1073-1083

ISSN 2614-5278 (media cetak), ISSN 2548-8368 (media online)

Available Online at https://ejurnal.stmik-budidarma.ac.id/index.php/mib DOI 10.30865/mib.v5i3.3029

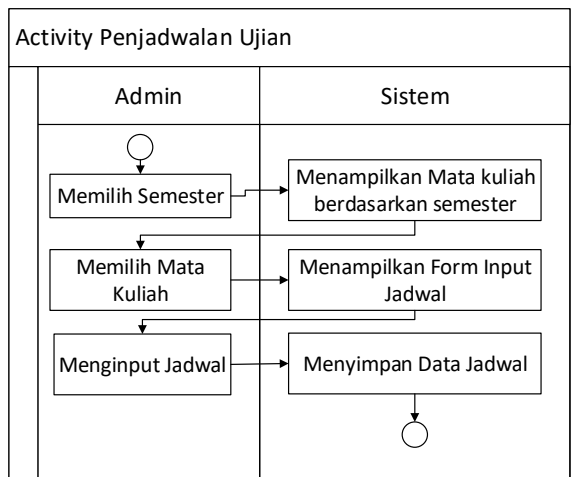

Gambar 6. Activity penjadwalan Ujian

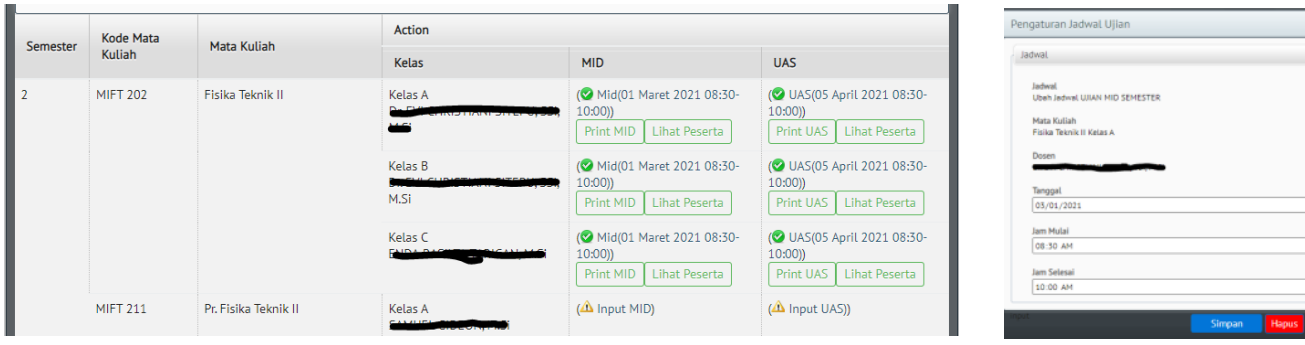

Gambar 7. Interface input jadwal ujian a) tampilan mata kuliah b)tampilan set jam ujian

b. Proses Penginputan Soal

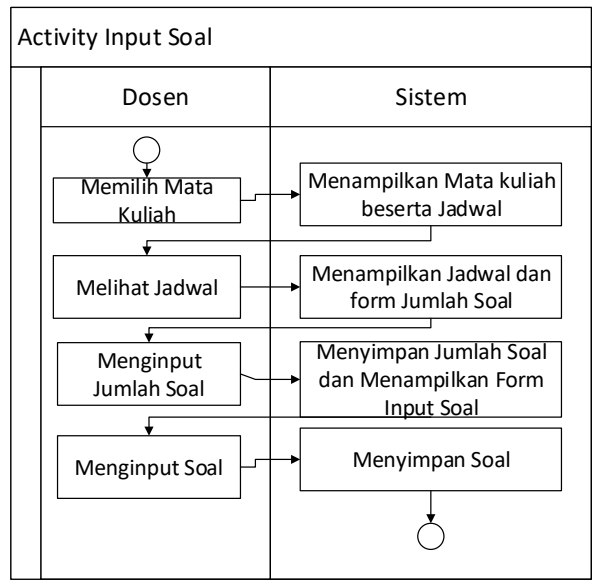

Gambar 8. Activity input soal

Sebelum menginput soal dosen diwajibkan untuk menentukan jumlah soal terlebih dahulu karena jumlah soal tersebut akan digunakan sebagai looping untuk menggunakan fitur ckeditor yang digunakan sebagai wadah untuk mengedit soal. Pada tampilan gambar 9 tiap nomor akan tampil CKEDITOR yang menjadi kolom untuk menginput soal. Untuk memasukkan gambar, disediakan tombol khusus di mana gambar akan di upload dapat di drag atau di copy ke dalam kolom soal.

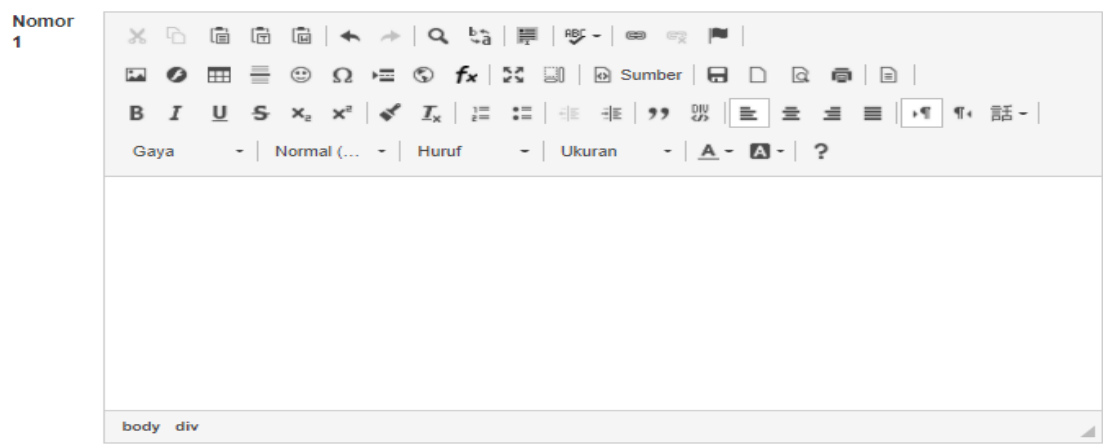

Gambar 9. Tampilan input soal untuk dosen 
JURNAL MEDIA INFORMATIKA BUDIDARMA

Volume 5, Nomor 3, Juli 2021, Page 1073-1083

ISSN 2614-5278 (media cetak), ISSN 2548-8368 (media online)

Available Online at https://ejurnal.stmik-budidarma.ac.id/index.php/mib DOI 10.30865/mib.v5i3.3029

c. Proses validasi soal ujian

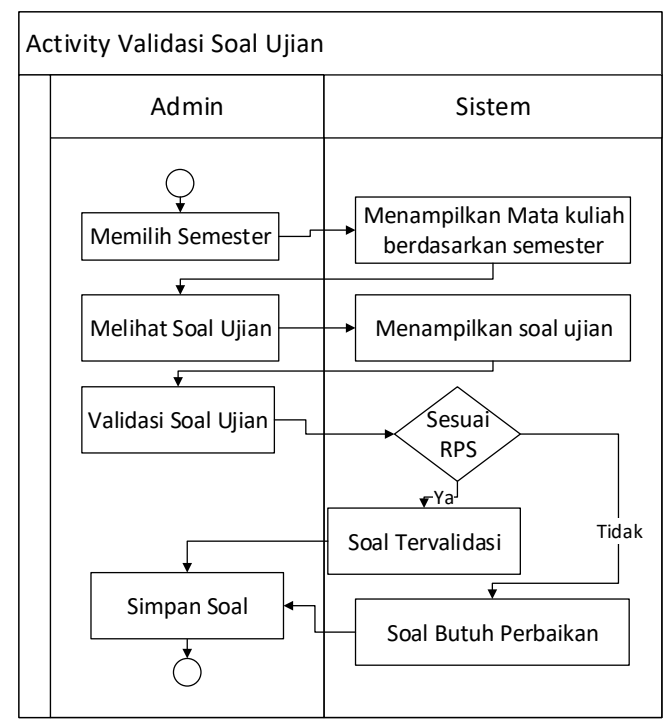

Gambar 10. Activity validasi soal ujian

Sebelum soal dapat dilihat oleh mahasiswa terlebih dahulu soal akan divalidasi oleh pihak program studi untuk memastikan soal memiliki kelengkapan misal seperti ada soal yang gambar tidak sesuai dengan soal ataupun point tiap soal tidak ditentukan.

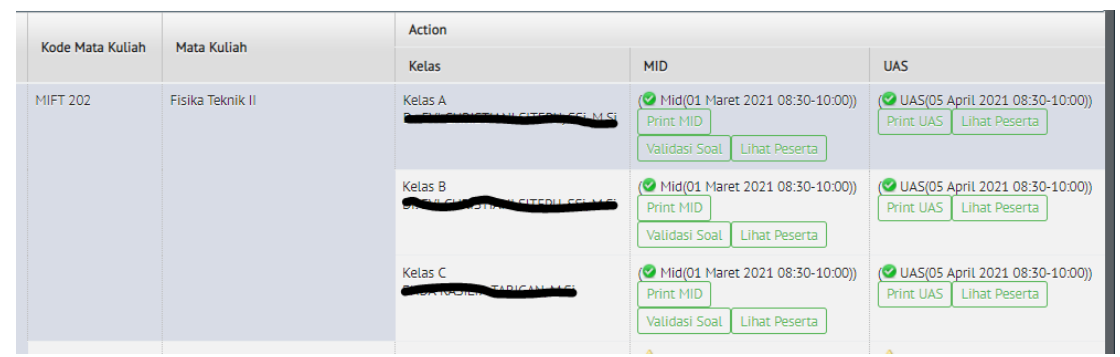

Gambar 11. Validasi Soal Ujian

d. Tampilan Ujian Mahasiswa

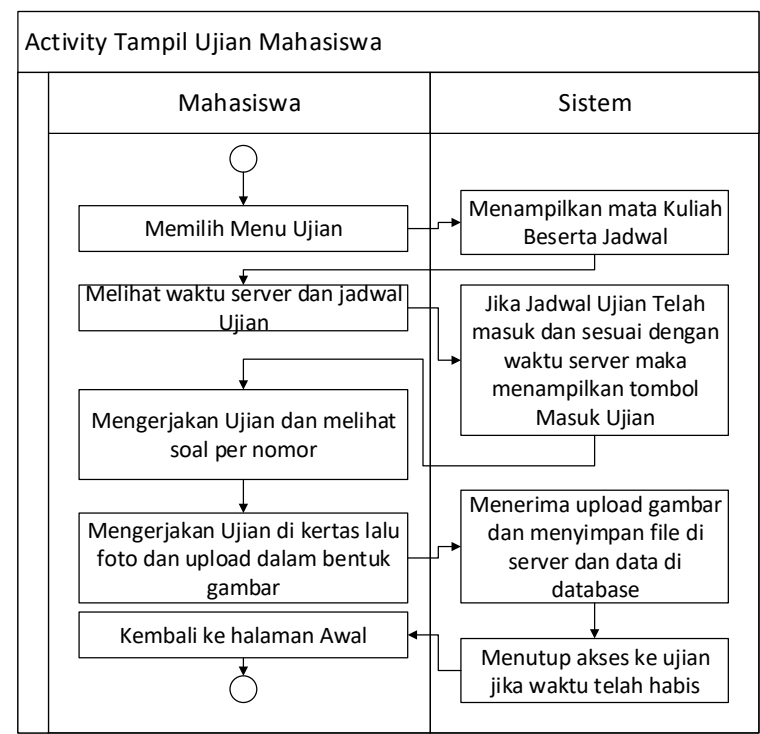

Gambar 12. Activity Tampilan Ujian Mahasiswa

Soal hanya dapat dikerjakan jika dosen yang bersangkutan telah menginput soal dan di validasi oleh Program Studi. Tombol Ujian akan muncul sesuai jadwal yang ditentukan dan untuk memastikan tidak ada perbedaan waktu antara komputer mahasiswa dan server maka waktu server ditampilkan di halaman ujian. Saat pelaksanaan ujian mahasiswa akan menginput jawaban pada kolom yang telah ditetapkan seperti Gambar 13. Ataupun jawaban dapat di upload melalui tombol upload yang disediakan. Untuk menghindari besarnya file 
ISSN 2614-5278 (media cetak), ISSN 2548-8368 (media online)

Available Online at https://ejurnal.stmik-budidarma.ac.id/index.php/mib

DOI 10.30865/mib.v5i3.3029

upload ke server dibatasi tipe file upload yang diizinkan yaitu file gambar bertipe jpeg, png, jpg. Untuk memastikan jawaban telah tersimpan ke database maka jawaban yang di input akan ditampilkan di Jawaban Tersimpan.

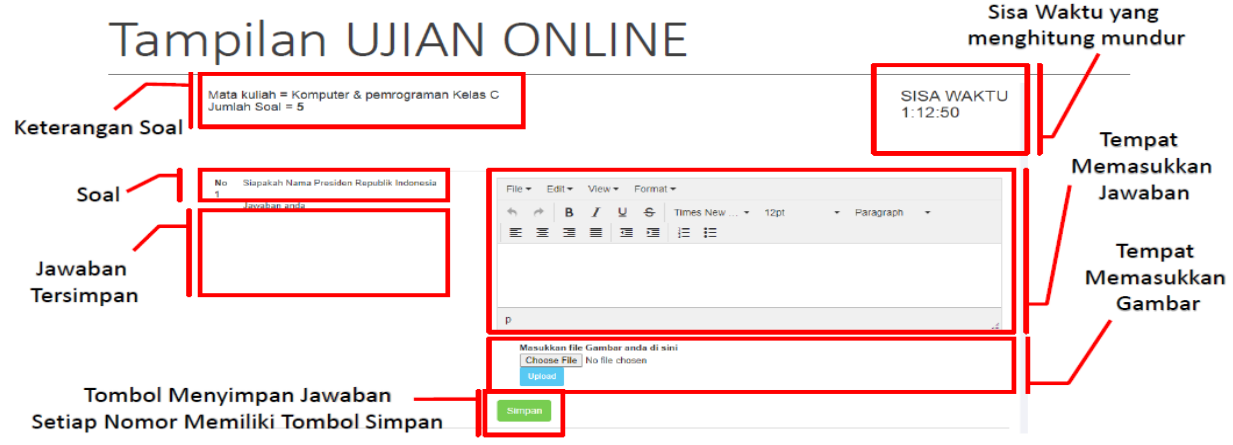

e. Memeriksa Hasil Ujian

Gambar 13. Tampilan saat melaksanakan ujian

\begin{tabular}{|c|c|c|}
\hline \multicolumn{2}{|c|}{ Activity Dosen memeriksa jawaban } \\
\hline Dosen & Sistem \\
\hline $\begin{array}{c}\text { Memilih Mata } \\
\text { Kuliah }\end{array}$ & $\rightarrow \begin{array}{c}\text { Menampilkan Mata kuliah } \\
\text { beserta Jadwal }\end{array}$ \\
\hline $\begin{array}{c}\text { Memilih Hasil } \\
\text { Ujian }\end{array}$ & $\rightarrow$ Menampilkan Hasil Ujian \\
\hline $\begin{array}{c}\text { Memilih } \\
\text { Mahasiswa }\end{array}$ & $\rightarrow \begin{array}{c}\text { Menampilkan Jawaban } \\
\text { Mahasiswa }\end{array}$ \\
\hline $\begin{array}{c}\text { Mengklik gambar } \\
\text { sebagai jawaban } \\
\text { mahasiswa }\end{array}$ & $\rightarrow \begin{array}{c}\text { Mengaktifkan fitur ezoom } \\
\text { untuk memperbesar atau } \\
\text { memutar gambar }\end{array}$ \\
\hline
\end{tabular}

Gambar 14. Activity Hasil Ujian

Dalam memeriksa hasil ujian dosen dapat melihat jam mulai serta jam selesai ujian mahasiswa tersebut. Selain itu untuk menjaga terjadinya kecurangan maka IP komputer dari perangkat yang digunakan di rekam sehingga dosen dapat melakukan analisa jika terdapat jawaban yang hampir mirip. Terdapat 2 cara untuk melihat jawaban mahasiswa yaitu : 1. Jawaban berdasarkan Mahasiswa di mana dosen dapat melihat jawaban dari mahasiswa yang bersangkutan mulai dari nomor 1 sampai dengan nomor terakhir. 2. Jawaban berdasarkan soal sehingga dosen dapat melihat rangkuman jawaban dari mahasiswa berdasarkan soal untuk membandingkan tingkat kesamaan dari mahasiswa yang satu dengan lainnya berdasarkan soal yang mereka kerjakan.

\subsection{Analisis Metode Ujian}

Dalam pengembangan sistem ujian online yang ada di PTKI Medan terdapat 2 kali perubahan, yang disajikan dalam metode berikut :

a. Metode Pertama berbasis Text

Metode ini merupakan metode awal yang di implementasikan pada semester Ganjil 2020/2021 di mana mahasiswa akan menginput jawaban pada kolom yang telah disediakan seperti pada Gambar 13. Dengan metode ini mahasiswa lebih mudah untuk melakukan share jawaban ke mahasiswa yang lain dengan cara copy paste jawaban berbentuk text seperti yang terlihat pada Gambar 15 mahasiswa tersebut membutuhkan waktu 25 menit untuk menyelesaikan jawaban. Metode ini sangat rentang terhadap kecurangan.
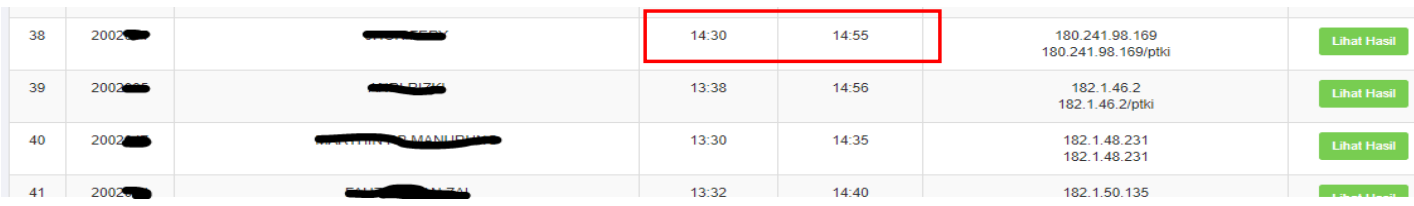

Gambar 15. Waktu Menyelesaikan Ujian 
ISSN 2614-5278 (media cetak), ISSN 2548-8368 (media online)

Available Online at https://ejurnal.stmik-budidarma.ac.id/index.php/mib DOI 10.30865/mib.v5i3.3029

b. Metode Kedua berbasis File

Pada metode ini yang di aplikasikan pada semester Genap 2020-2021, kolom jawaban untuk text dihilangkan diganti dengan upload file gambar untuk jawaban. Sehingga jawaban yang dikumpulkan adalah foto dari tulis tangan mahasiswa tersebut saat ujian.

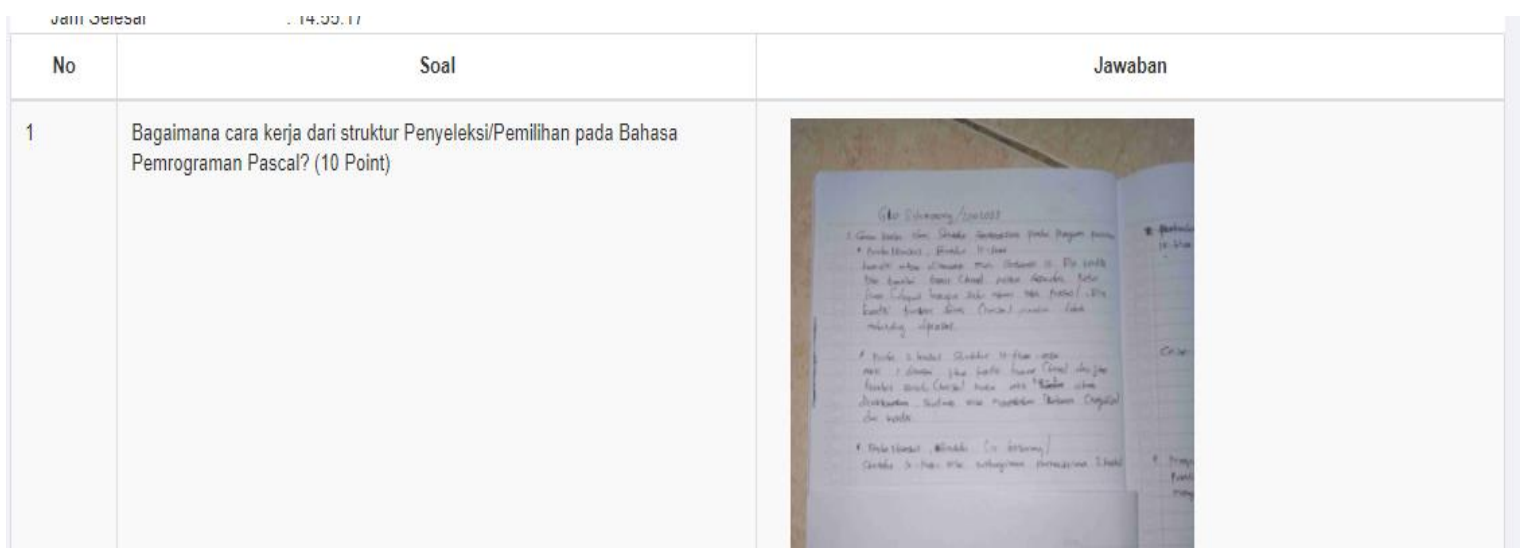

Gambar 16. Tampilan input jawaban pada Portal Mahasiswa

Seperti pada Gambar 16 mahasiswa harus menulis jawaban pada kertas jawaban atau kertas kosong lalu menguload pada kolom jawaban yang disediakan.

Berdasarkan Metode 1 dan Metode 2 pada grafik Gambar 17, pada metode 2 terdapat 2 titik yang menandakan terjadi eror saat ujian online yang memiliki nilai 0 sedangkan pada metode 1 terdapat 4 titik yang memiliki nilai 0 yang menandakan ada 4 orang yang memiliki eror saat melakukan ujian. Perbandingan ini merupakan rata-rata waktu pengerjaan ujian untuk 5 mata kuliah terhadap mahasiswa.

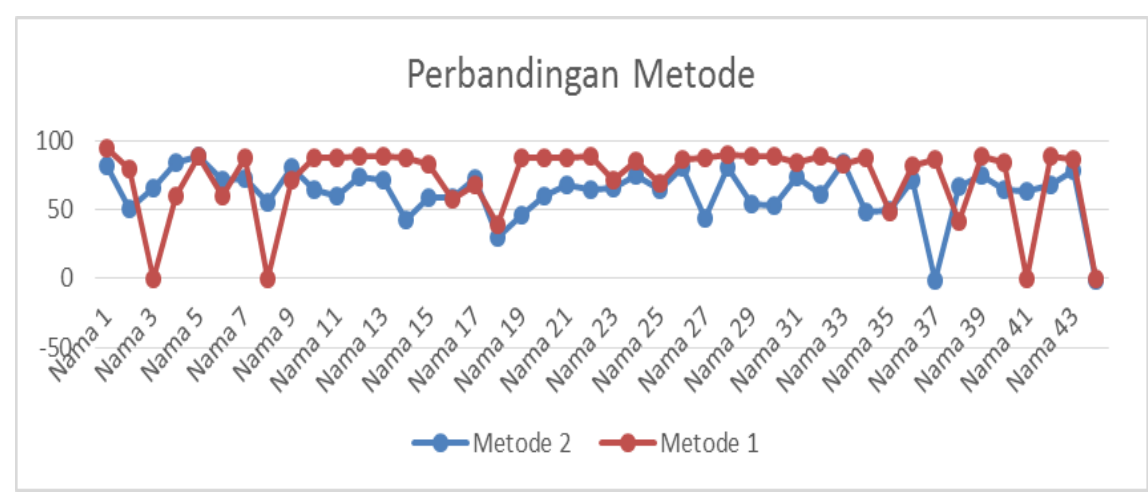

Gambar 17. Perbandingan Metode 1 dan Metode 2

Pada Gambar 18 terdapat 44 sampel dan Gambar 19 terdapat 76 sampel, merupakan hasil pemilihan sampel di mana untuk jumlah peserta ujian 40, 41, 42 dan 43 orang di kumpulkan dan di data jumlah file yang di upload. Terlihat pada sampel dalam metode 1 jumlah file dalam satu ujian mata kuliah memiliki jumlah file lebih besar dari 300 file bahkan ada yang mencapai 500 file dalam salah satu sampel yaitu 43 peserta ujian dalam mata kuliah yang ke 3. Berbeda dengan metode 2 di mana rata-rata jumlah file dalam satu ujian mata kuliah 200-250 file dan hanya 1 mata kuliah yang lebih dari 300 file yaitu pada peserta 43 orang untuk sampel mata kuliah yang ke 15

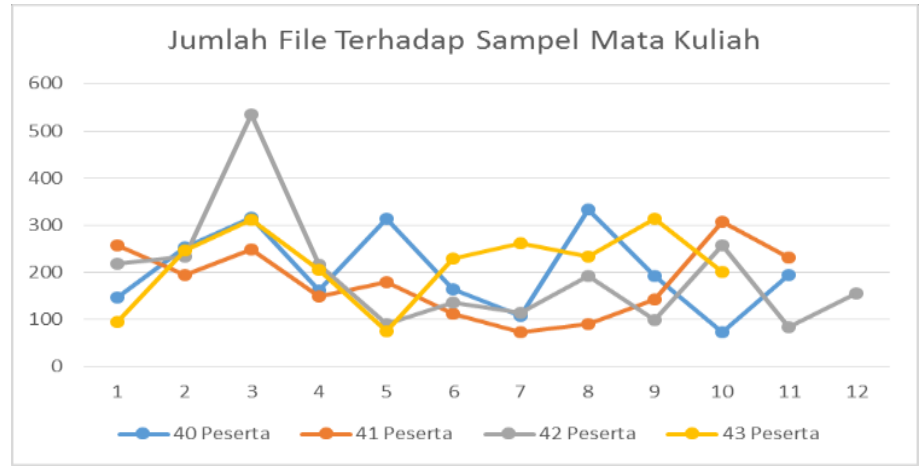

Gambar 18. Grafik Jumlah File Terhadap Sampel Peserta untuk Metode 1 
ISSN 2614-5278 (media cetak), ISSN 2548-8368 (media online)

Available Online at https://ejurnal.stmik-budidarma.ac.id/index.php/mib DOI 10.30865/mib.v5i3.3029

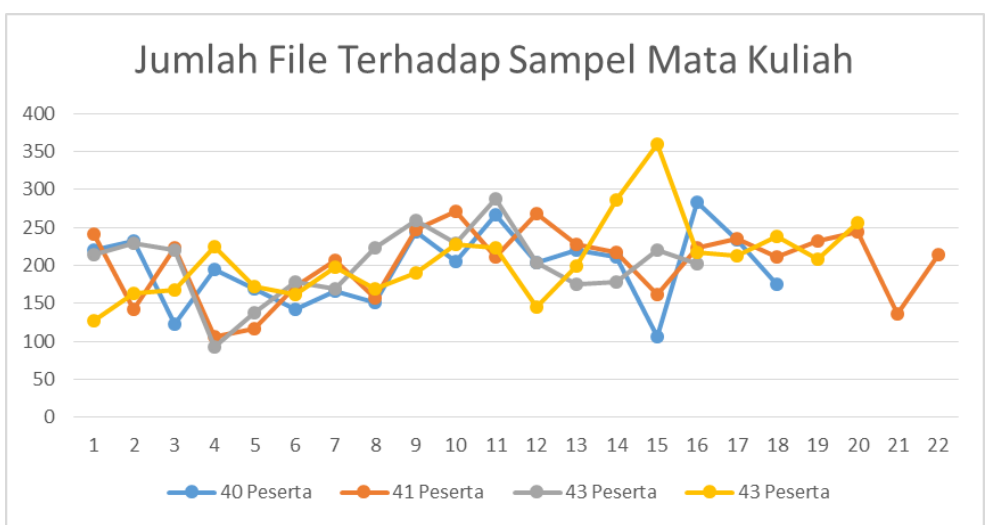

Gambar 19. Grafik Jumlah File Terhadap Sampel Peserta untuk Metode 2

Tabel 2. Perbandingan Metode 1 dan Metode 2 untuk penggunaan File

\begin{tabular}{ccccccc}
\hline $\begin{array}{c}\text { Ujian Yang } \\
\text { memiliki Jumlah } \\
\text { Mahasiswa }\end{array}$ & $\begin{array}{c}\text { Total } \\
\text { File }\end{array}$ & $\begin{array}{c}\text { Mumlah Mata } \\
\text { Kuliah }\end{array}$ & $\begin{array}{c}\text { Rata- } \\
\text { rata }\end{array}$ & $\begin{array}{c}\text { Total } \\
\text { File }\end{array}$ & $\begin{array}{c}\text { Metode 2 } \\
\text { Kumlah Mata } \\
\text { Kuliah }\end{array}$ & $\begin{array}{c}\text { Rata- } \\
\text { rata }\end{array}$ \\
\hline 40 & 2255 & 11 & 205 & 3553 & 18 & 197 \\
41 & 1985 & 11 & 180 & 4477 & 22 & 204 \\
42 & 2333 & 12 & 194 & 3224 & 16 & 202 \\
43 & 2170 & 10 & 217 & 4152 & 20 & 208 \\
\hline
\end{tabular}

Dari grafik tersebut dapat disimpulkan bahwa terjadi peningkatan jumlah file yang di upload dari metode 1 ke metode 2 tetapi rata-rata file dalam 1 mata kuliah lebih stabil dengan metode yang ke 2. Pada Tabel 2 di sajikan data jumlah peserta ujian dengan metode 1 dan 2, yang berarti pada baris pertama jumlah mahasiswa yang mengikuti ujian adalah 40 orang dengan jumlah mata kuliah yang memiliki 40 orang peserta ujian sebanyak 11 mata kuliah, dari ke 11 mata kuliah tersebut terdapat 2255 jumlah file yang di upload dan di peroleh rata-rata 1 mata kuliah untuk peserta ujian 40 orang pada metode 1 adalah 205 file.

\subsection{Analisis Pemrograman}

a. Kompresi Gambar

Untuk mengatasi agar server tidak dibebani dengan menerima upload foto dari jawaban mahasiswa selain membatasi maksimum yang size yang dapat diterima adalah 2,5 Mb dilakukan juga kompresi file gambar yang di upload dengan menurunkan kualitas gambar ke tingkat tertentu menggunakan fungsi compressedImage (\$filesoal ["tmp_name"], \$location,20); yang ada di php dengan pengaturan kualitas gambar akan menjadi $20 \%$ dari $100 \%$ dan ini akan berpengaruh terhadap file yang tersimpan di sistem. Berdasarkan Tabel 2 , file gambar yang lebih besar $200 \mathrm{~kb}$ terjadi pengurangan size maksimal sampai $78,48 \%$, dan terjadi gagal upload pada file ke 4 karena file tersebut memiliki ukuran file lebih besar dari syarat yaitu 2,5 Mb.

Hasil kompresi dapat dilihat pada tabel berikut :

Tabel 3. Hasil kompresi file gambar

\begin{tabular}{cccccc}
\hline No & Nama File & $\begin{array}{c}\text { Ukuran } \\
\text { Sebelum }\end{array}$ & $\begin{array}{c}\text { Ukuran } \\
\text { Sesudah }\end{array}$ & $\begin{array}{c}\text { Pengurangan } \\
(\%)\end{array}$ & Keterangan \\
\hline 1 & Asli 1.jpg & $198 \mathrm{~Kb}$ & $198 \mathrm{~Kb}$ & 0,00 & \\
2 & Asli 2.jpg & $883 \mathrm{~Kb}$ & $434 \mathrm{~Kb}$ & 50,85 & \\
3 & Asli 3.jpg & $1896 \mathrm{~Kb}$ & $435 \mathrm{~Kb}$ & 77,06 & Gagal Di upload \\
4 & Asli 4.jpg & $3218 \mathrm{~Kb}$ & - & - & \\
5 & Asli 5.jpg & $440 \mathrm{~Kb}$ & $101 \mathrm{~Kb}$ & 77,05 & \\
6 & Asli 6.png & $1329 \mathrm{~Kb}$ & $286 \mathrm{~Kb}$ & 78,48 & \\
\hline
\end{tabular}

b. Melihat Hasil Jawaban

Untuk melihat jawaban teknik yang digunakan adalah dengan menampilkan gambar yang di upload seperti pada gambar 21. Gambar yang diupload mungkin akan terlihat kecil tetapi pada proses tampilan pemeriksaan ini diberi tambahan fitur zoom untuk memperbesar ataupun membalik gambar dengan fitur ezoom.js (https://www.jqueryscript.net/zoom/image-viewer-ezoom.html) karena dalam proses ujian akan ada kesalahan beberapa mahasiswa saat melakukan upload gambar secara terbalik. Dan ini akan mempengaruhi proses pemeriksaan oleh dosen yang bersangkutan. Ezoom.js merupakan salah satu javascript yang dapat di download dari internet dan terdapat lisensi Free-nya. javascript tersebut dapat di pasang pada website yang berbasis php. 
ISSN 2614-5278 (media cetak), ISSN 2548-8368 (media online)

Available Online at https://ejurnal.stmik-budidarma.ac.id/index.php/mib DOI 10.30865/mib.v5i3.3029

\section{KESIMPULAN}

Dari Penelitian ini dapat disimpulkan bahwa sistem ujian kolektif essay dapat dilaksanakan dengan baik di PTKI Medan. Ujian kolektif memberi kelebihan tersendiri dalam hal pengadministrasian karena soal ujian dan jawaban akan terdata di database. Dalam membangun sistem ujian online berbasis website pastikan server dapat mendukung. Membuat ujian online essay sangat berbeda saat membuat ujian berbasis pilihan ganda, salah satu yang perlu di perhatikan adalah untuk meminimalkan kecurangan hindari penggunaan kolom jawaban di ketik, gunakan fitur upload baik berupa gambar maupun pdf. Penggunaan upload gambar juga perlu di perhatikan dengan memberi batas maksimum ukuran file ataupun memberi fitur kompres ukuran file agar tidak membebani server. Pada penelitian ini terdapat 2 metode yang disajikan tiap metode memiliki kelebihan masing-masing, untuk metode 1digunakan sebanyak 44 sampel sedangkan untuk metode 2 digunakan sebanyak 76 sampel. Masing-masing metode terdapat sampel jumlah mahasiswa per mata kuliah adalah 40,41,42,43 orang. Maksimum size file yaitu 2,5 Mb lebih dari size tersebut maka akan di tolak, kurang dari size tersebut akan di kompres. Untuk data yang memiliki ukuran besar dapat dikompres hingga 78\%. Dalam membangun sistem inform asi juga perlu diperhatikan untuk menggunakan fitur yang memudahkan pengguna salah satunya adalah memudahkan dosen dalam memeriksa jawaban dengan memanfaatkan fitur ezoom.js sebagai sarana untuk view jawaban dalam bentuk gambar yang digunakan untuk memperbesar, memperkecil, memutar gambar jawaban.

\section{REFERENCES}

[1] R. H. S. Aji, "Dampak Covid-19 pada Pendidikan di Indonesia: Sekolah, Keterampilan, dan Proses Pembelajaran," SALAM J. Sos. dan Budaya Syar-i, vol. 7, no. 5, pp. 395-402, 2020.

[2] H. D. Nugraha, D. Poniman, R. A. V. Kencanasari, A. Maosul, and M. I. Rusydi, "Meta-Analisis Model Pembelajaran Vokasi dalam Kondisi Covid-19," J. Din. Vokasional Tek. Mesin, vol. 5, no. 2, pp. 83-94, 2020.

[3] S. Gideon and A. A. Rahmansyah, "Implementasi Pembelajaran Sinkronus pada Mata Kuliah Fisika 1 Menggunakan Discord Dipadukan dengan Google Jamboard dan Powerpoint," Phys. Educ. Res. J., vol. 3, no. 1, pp. 1-10, 2021.

[4] R. Arifin, R. Ratnawati, and A. Kunda, "Implementasi Sistem Ujian Berbasis Online Pada Ujian Esai Bahasa Indonesia," Inspir. J. Teknol. Inf. dan Komun., vol. 8, no. 2, pp. 81-88, 2018.

[5] Kadariah, "Evaluasi Penyelenggaraan Ujian Akhir Semester Mahasiswa Program Non Pendidikan Dasar Di Upbjj-U Makassar," JEKPEND J. Ekon. dan Pendidik., vol. 1, no. 1, pp. 97-105, 2018.

[6] D. Febyronita and Giyanto, "Survei Tingkat Kemampuan Siswa dalam Mengerjakan Tes Berbentuk Jawaban Singkat (Short Answer Test) Pada Mata Pelajaran IPS Terpadu (Geografi) Kelas VII di SMP Negeri 1 Mesuji Tahun Pelajaran 2015/2016," J. Swarnabhumi, vol. 1, no. 1, pp. 17-21, 2016.

[7] R. E. Pratama and S. Mulyati, "Pembelajaran Daring dan Luring pada Masa Pandemi Covid-19," Gagasan Pendidik. Indones., vol. 1 , no. 2 , p. 49,2020

[8] J. Zeniarja, A. Salam, and I. Achsanu, "Sistem Koreksi Jawaban Esai Otomatis (E-Valuation) dengan Vector Space Model pada Computer Based Test (CBT)," Semin. Nas. Din. Inform ., pp. 91-96, 2020.

[9] H. K. Bharata and H. Sulistyowati, "Optimasi Sistem Penilaian Ujian Essay Online Menggunakan Support Vector Machine (SVM) Dan Latent Semantic Analysis (LSA) Dengan Bahasa R,” Sci. J. Inf. Syst. Technol. Appl. Comput. Eng., vol. 10, no. 2, pp. 63-70, 2020.

[10] S. Bahri and R. Wajhillah, "Optimalisasi Algoritma Rabin Karp menggunakan TF-IDF Dalam Pencocokan Text Pada Penilaian Ujian Essay Otomatis,” InfoTekJar J. Nas. Inform . dan Teknol. Jar., vol. 4, no. 2, pp. 292-295, 2020.

[11] A. D. Sipayung, Fauziah, and Nurhayati, "Sistem Aplikasi Penilaian Jawaban Essay Test Calon Karyawan PT Siloam Hospitals TB Simatupang Menggunakan Algoritma Text Mining TF-IDF Berbasis Web," J. Media Inform . Budidarma, vol. 4, no. 4, pp. 872-878, 2020.

[12] R. Ariansah and W. Haryono, "Rancang Bangun Simulasi Ujian Online Berbasis Web Pada Smk Satria," J. Chem. Inf. Model., vol. 1, no. 1, pp. 51-59, 2021.

[13] Riyanto, "Rancang Bangun Sistem Infomasi Ujian Online Untuk Siswa Sekolah Menengah Kejuruan Berbasis Website di SMK Negeri 1 Ngawen," Klaten, 2020

[14] R. Susanto and A. D. Andriana, "PERBANDINGAN MODEL WATERFALL DAN PROTOTYPING UNTUK PENGEMBANGAN SISTEM INFORM ASI," Maj. Ilm. UNIKOM, vol. 14, no. 1, pp. 41-46, 2016.

[15] A. Firman, H. F. Wowor, and X. Najoan, "Sistem Inform asi Perpustakaan Online Berbasis Web," E-journal Tek. Elektro dan Komput., vol. 5, no. 2, pp. 29-36, 2016.

[16] O. Pahlevi, A. Mulyani, and M. Khoir, "Sistem Inform asi Inventori Barang Menggunakan Metode Object Oriented Di Pt. Livaza Teknologi Indonesia Jakarta," J. PROSISKO, vol. 5, no. 1, pp. 27-35, 2018.

[17] R. Safitri, "Simple Crud Buku Tamu Perpustakaan Berbasis Php Dan Mysql:Langkah-Langkah Pembuatan,” J. Tibanndaru, vol. 2, no. 2, p. 40, 2018. 